Acta Poetica $32 \cdot 2$

JULIO-DICIEMBRE

$2011(177-210)$

\title{
Menipo litigante, diálogo satírico de Bartolomé Leonardo de Argensola, en la prensa reformista
}

\author{
Isabel Pérez Cuenca
}

Menipo litigante, diálogo de Bartolomé Leonardo de Argensola, fue publicado por vez primera en un papel periódico con intereses literarios del último tercio del siglo XVIII, cuyo título es La Espigadera. Este impreso, hasta ahora olvidado, pone de manifiesto notables diferencias textuales respecto de la única edición impresa llevada a cabo por Cipriano Muñoz y Manzano - Conde de la Viñaza-, en el siglo XIX, así como de los manuscritos conocidos. El objeto de este trabajo es dar a conocer y analizar este ignorado testimonio y dos manuscritos que también transmiten el diálogo.

Palabras Clave: Bartolomé Leonardo de Argensola, Menipo litigante, sátira, siglo XVII, La Espigadera, Prensa Española, Siglo XVIII.

Menipo litigante, Bartolomé Leonardo de Argensola's dialogue, was first published towards the end of the 18th Century in the literary journal: La Espigadera. This published text, forgotten until now, reveals substantial textual differences with the only other printed edition, which was published by Cipriano Muñoz y Manzano - Conde de la Viñaza - in the 19th Century, as well as with other known manuscripts. The aim of this article is to raise awareness of and analyse this unknown edition along with a further two texts which contain the dialogue.

Keywords: Leonardo de Argensola, Menipo Litigante, satire, 17th Century, La Espigadera, Spanish Journalism, 18th Century.

Fecha de recepción: 23 de abril de 2010

Fecha de aceptación: 30 de julio de 2010 

Isabel Pérez Cuenca

Universidad CEU San Pablo, Madrid, España

\section{Menipo litigante, diálogo satírico de Bartolomé Leonardo de Argensola, en la prensa reformista ${ }^{1}$}

\section{Introducción ${ }^{2}$}

En el año de 1778, Juan Antonio Pellicer y Saforcada ve impreso su Ensayo de una biblioteca de traductores españoles precedido de, entre otras, unas noticias literarias sobre la vida del Rector de Villahermosa, Bartolomé Leonardo de Argensola. En las mencionadas noticias, incluye Pellicer un "Catálogo de las obras inéditas" del autor aragonés con ocho entradas, la sexta destinada a dar a conocer los diálogos titulados Menipo, Demócrito y Dédalo, de los que dice:

Son tres Dialogos, obra propia de nuestro Coronista. El primero contra los malos Jueces y Abogados: el segundo contra diversas locuras de los hombres: en el tercero cifra las prisiones de Antonio Perez [...]. Estos son los Dialogos tan sazonados, que por

${ }^{1}$ Este trabajo se inscribe en el proyecto financiado por la Comunidad de Madrid S2007 HUM-0425.

${ }^{2}$ Menipo litigante, Demócrito y Dédalo, de Bartolomé Leonardo de Argensola, se han publicado de nuevo con el título de Sátiras menipeas, L. Schwartz e I. Pérez Cuenca, Zaragoza (ed.), Prensas Universitarias, 2011 (en prensa). 
justos respetos no se dan a la prensa (Pellicer, Ensayo de una biblioteca, 114). ${ }^{3}$

Unos veinte años después se publica la Biblioteca nueva de los escritores aragoneses de Félix de Latassa y Ortín (1799, t. II), en la que se vuelve a hacer referencia a Menipo litigante junto con los otros dos diálogos, Demócrito y Dédalo; los términos empleados aquí para describir estas obras son calco de las palabras de Pellicer. Los tres textos se siguen suponiendo inéditos, pues no hay mención a impreso alguno, aunque sí se señala que "hay muchas copias de ellos" (Latassa, Biblioteca nueva, t. II, 470).

Tendrán que transcurrir casi cien años para que se impriman los tres diálogos del escritor aragonés. El primero, publicado en el año 1887, será Menipo, que se incluirá en la edición de Algunas obras satíricas inéditas de Lupercio y Bartolomé Leonardo de Argensola preparada por Cipriano Muñoz y Manzano, Conde de la Viñaza (1887). En la introducción a las obras satíricas seleccionadas, el editor utiliza de paradigma, para ponderar la vena satírica de los hermanos Argensola, una carta que Bartolomé remite al Conde de Lemos y los diálogos de este:

El númen satírico — dice la Viñaza - de los Argensola, hállase definido con acabada exactitud, en una epístola inédita, dirigida por el Rector de Villahermosa al Conde de Lemos y que es un capítulo de arte poética, en el que palpitan los entusiasmos reflexivos de Bartolomé hacia las doctrinas horacianas y aristotélicas, una cartilla de preceptos acerca de la sátira del venusino; el credo literario de un grande hombre, escrito en páginas esmaltadas de la erudición más selecta (Viñaza, Algunas obras satíricas, 10).

${ }^{3}$ El autor del Ensayo de una biblioteca de autores españoles imprime, a continuación del "Catálogo de obras inéditas", el Diálogo de Mercurio y la Virtud, traducción realizada por Bartolomé Leonardo de Argensola del de Luciano (115-118). 
Bartolomé escribió [...] tres Diálogos hasta el día inéditos, en los que lució $[\ldots]$ su vis juvenalesca unas veces y horaciana otras. [...] El corte de estos Diálogos es lucianesco y clásico; y su mérito, solo comparable, al de las joyas de este género, que nos legaron Valdés, Villalobos, Guevara y el Bachiller Rhua (24).

Además de ensalzar el genio del Rector con la mención a los textos referidos, opta por la impresión de la epístola (Leonardo de Argensola, "Carta del Rector de Villahermosa", 29-32) y, como dije, del diálogo titulado Menipo (Leonardo de Argensola, "Menipo litigante", 59-68). En esta ocasión, para ambos textos, se limita a llevar a cabo una mera transcripción del manuscrito de la Biblioteca Nacional de España M. 251 (signatura antigua), es decir, ms. 4141 (signatura moderna).

Pasados dos años, en 1889, el Conde de la Viñaza imprime por vez primera Menipo, Demócrito y Dédalo juntos en Obras sueltas de Lupercio y Bartolomé Leonardo de Argensola. ${ }^{4} \mathrm{Se}$ sirve ahora de un total de tres manuscritos para la edición de los diálogos, todos de la colección de la Biblioteca Nacional de España: M. 251, I. 205 y T. $106 .^{5}$

El ms. 4141, en cuyo título reza Obras de Argensola manuscritas, con mano del siglo XVII, transmite, fundamentalmente, obras de los hermanos aragoneses, entre las que se incluye el diálogo Menipo litigante (537-566) y la carta dirigida al Conde de Lemos. El ms. 2844 transcribe los tres diálogos editados por

${ }^{4}$ Los diálogos pueden leerse en Menipo 107-130, Demócrito 131-145, y Dédalo $161-188$ del t. II.

${ }^{5}$ El Conde de la Viñaza dará cuenta oportuna, en nota a pie de página al comienzo de cada diálogo, del manuscrito que decide editar (Obras sueltas de Lupercio y Bartolomé, t. II, 107, 131 y 161). En el caso de Dédalo amplía la información sobre los manuscritos empleados: "parece continuación ó segunda parte de otro diálogo; pero en el Ms. T-106 de la Biblioteca Nacional no existe, y sólo se encuentra en la forma en que lo publicamos". La correspondencia entre asignaturas antiguas y modernas es la siguiente: M. 251 (ms. 4141), I. 205 (ms. 2844) y T. 106 (ms. 6861). A partir este momento me referiré a los manuscritos de la Biblioteca Nacional de Madrid por sus signaturas modernas. 
el Conde de la Viñaza; se trata de una copia del siglo XVIII, cuya unidad reside en reunir los tres diálogos de Bartolomé Leonardo de Argensola (Menipo litigante: ff. 1r-37v; Demócrito: ff. 39r-78r, y Dédalo: ff. 79r-111r) junto a dos diálogos y otros textos de Luciano de Samosata, tal como se indica en el tejuelo: "Leonardo Diálogos y Luciano". Por último, en el ms. 6861 nos encontramos con una cuidada copia del siglo XVII, protegida por una encuadernación de época realizada en tafilete rojo y embellecida con hierros y cortes dorados, de los diálogos Menipo (ff. 2r-28v), Demócrito (ff. 33r-66r) y Dédalo (ff. 69r95v). ${ }^{6}$

Para la edición de Menipo litigante, Muñoz y Manzano se basa en el ms. 4141 y corrige con los manuscritos 6861 y 2844; mientras que para Demócrito y Dédalo emplea el manuscrito 6861, por ser copia del XVII y no disponer en el ms. 4141 de testimonio de alguno de ellos.

Nuevos testimonios de Menipo litigante:

Dos manuscritos y uno impreso

Cuando el Conde de la Viñaza preparó las dos ediciones del diálogo Menipo litigante desconocía la existencia de otros testimonios, entre ellos dos manuscritos que se hallan uno en España y otro en Estados Unidos:

1. Ms. de la Colección Borbón-Lorenzana, signatura ms. 521 de la Biblioteca Pública de Toledo, actualmente Biblioteca de Castilla-La Mancha. De los tres diálogos de

${ }^{6}$ Los tres manuscritos se encuentran descritos en Inventario 1970-1987, vols. IX-XI. Además véase para el ms. 4141 la descripción de J.M. Blecua ("Manuscritos e impresos", vol. I, LXIII-LXIV). Es de especial interés la observación que añade Blecua al final: "El colector fué amigo de Bartolomé Leonardo, según se desprende de ciertas notas marginales. Contiene algunos autógrafos [...]". 
Bartolomé Leonardo de Argensola que ahora nos ocupan, transmite Menipo (ff. 354r-375v) y Demócrito (ff. 376r$395 \mathrm{v}$ ), aparte de varios poemas de ambos hermanos, otros de Galcerán de Borja y un soneto de Espinel; dos tragedias de Lupercio; una falsa atribución a Bartolomé de la Epístola moral a Fabio, y otro diálogo de este último titulado Luciano. ${ }^{7}$

2. Ms. procedente de la Biblioteca de Salvá ${ }^{8}$ que, posteriormente, pasó a la biblioteca particular del hispanista francés Foulchè-Delbosc, ${ }^{9}$ hoy en la biblioteca de la Universidad de Pensilvania, con signatura ms. codex $184 .{ }^{10}$ Entre las obras de los hermanos Argensola se encuentran los diálogos de Bartolomé titulados Menipo (ff. 343v-357r), Demócrito (ff. 325v-343r), además del de Luciano. ${ }^{11}$

Sabemos de otro manuscrito más de los diálogos Dédalo y Demócrito en paradero desconocido. Se trata de un volumen procedente de la biblioteca del canónigo penitenciario de Zaragoza, don Manuel Turmo y Palacios, el cual, como otros eruditos del siglo XVIII, llegó a formar una digna colección que se dispersó tras su muerte (1788), yendo a parar muchos de sus ejemplares a manos de bibliófilos del siguiente siglo que, en

\footnotetext{
${ }^{7}$ Véase la descripción realizada por Francisco Esteve Barba, Catálogo de la colección, 439-451. Este mismo manuscrito fue descrito por José Manuel Blecua ("Manuscritos e impresos", vol. I, LXIII); actualmente puede consultarse una descripción y digitalización del manuscrito de la colección Borbón-Lorenzana en Biblioteca Virtual del Patrimonio Bibliográfico, núm. de control BVPB20070007723 $<$ http://bvpb.mcu.es/es/catalogo_imagenes/grupo.cmd?path=11000706 $>$ [fecha de consulta: febrero, 2009].

${ }^{8}$ Pedro Salvá y Mallén, Catálogo de la Biblioteca de Salvá, t. I, 259-260, n. 729.

${ }^{9}$ Sobre este manuscrito véase Foulchè-Delbosc, "Pour une édition des Argensolas", XLVIII, 113, 318-319.

${ }^{10}$ Norman P. Zacour y Rudolf Hirsch, Catalogue of Manuscripts, 141-142.

${ }^{11}$ Este manuscrito no he podido consultarlo y estudiarlo, solo dispongo de reproducción de los diálogos Menipo y Demócrito. José Manuel Blecua incluye también descripción de este en Lupercio y Bartolomé Leonardo de Argensola ("Manuscritos e impresos", vol. I, LXI-LXII).
} 
algunos casos, legaron parte de esos libros a la Biblioteca Nacional. Latassa describió este manuscrito por vez primera en Memorias literarias de Aragón, ${ }^{12}$ y vuelve a hacer referencia a él en Biblioteca nueva de los escritores aragoneses:

El referido canónigo Turmo poseyó tambien algunas [poesías] en un tomo Miscelaneo que parece original, y se titula: Obras del Retor Bartholomè Leonardo de Argensola, Canonigo de la Seo de Zaragoza, y coronista del Rey nuestro Señor y del Reyno de Aragon. Consta de 73 ojas en $4^{\circ}$. En el están las Rimas publicadas y 22 poesias mas que no se han impreso entre las de 1634. Alli existen tambien los Dialogos de Dedalo y Democrito. El primero ocupa 27 ojas y el segundo 28. No està el Menipo (t. II, 469).

Por la detallada descripción que Latassa confecciona de este manuscrito, tenemos que pensar que lo tuvo en sus manos; además, en el "Prefacio" a la Biblioteca antigua de los escritores aragoneses, afirma que "D. Manuel Turmo, Canonigo Penitenciario de Zaragoza, que acaba de pasar à mejor vida, y tuvo la generosidad de franquearme su copiosa colección de Libros raros; y manuscritos, que juntó à costa de mucho trabajo y diligencia" (Biblioteca antigua, XIV). El manuscrito de Turmo, por tanto, reunía poesías inéditas de los Argensola junto a los autógrafos de Dédalo y Demócrito, pero no el Menipo, diálogo que nos ocupa.

En fin, de Menipo litigante, objeto de este trabajo, conozco un total de cinco manuscritos: $:^{13}$

${ }^{12}$ Se trata de una obra manuscrita en tres tomos. En el tomo II, Latassa transcribe el índice del manuscrito del canónigo Turmo, cuyo resumen puede leerse en Ricardo del Arco y Garay, La erudición española, 238-240, n. 26. Sobre el manuscrito Memorias literarias de Aragón de Félix Latassa, véase G. Lamarca Langa, "Memorias literarias".

${ }^{13}$ Finalizado este trabajo, hallé otra copia manuscrita de estas sátiras en la Real Academia Española, fondo Rodríguez Moñino y María Brey (signatura: RM-6672). 
Biblioteca Nacional de España:

- Ms. 4141, de letra del siglo XVII.

- Ms. 6861, copia del siglo XVII.

- Ms. 2844 de mano del siglo XVIII.

Biblioteca de Castilla-La Mancha:

- Ms. 521, copia del siglo XVII.

Biblioteca de la Universidad de Pensilvania:

- Ms. codex 184 de letra del siglo XVII.

A estos testimonios manuscritos, es posible sumar un impreso de Menipo litigante anterior a la edición de la Viñaza de 1887 e ignorado hasta hoy, distinto de todos los manuscritos conocidos. A esta impresión hace referencia el manuscrito de la colección Borbón-Lorenzana (ms. 521), pues esta copia está falta del comienzo del diálogo; laguna que fue rellenada por una mano del siglo XIX al transcribir de un texto impreso en el periódico literario La Espigadera, tal como se indica en nota: "Por faltar a este Diálogo su principio según se hecha de ver por la antigüedad de la letra se le copió del que se publicó en el Periódico Espigadera, número 7, año de 1790" (Biblioteca de Castilla-La Mancha, ms. 521, f. 354v).

Efectivamente, en el número 7 de La Espigadera, en las páginas 209-236, se imprime a una columna el texto de Bartolomé Leonardo de Argensola. Aparece sin mención de autor y no se publica con el título que transmiten los manuscritos conocidos, sino con un largo encabezamiento que hace referencia al tema del diálogo. ${ }^{14}$

${ }^{14}$ Se ha consultado el ejemplar que conserva la Biblioteca Nacional de España, signatura R/7167. 
La Espigadera, Obra Periódica, ${ }^{15}$ se publicó durante los años 1790 y 1791, previa solicitud de licencia por parte de Alfonso Valentín Bravo, fechada en Madrid, el 29 de mayo de 1789. La licencia le será concedida y firmada por el Licenciado Pedrosa, en Madrid, a 23 de noviembre de 1789:

Se concede a D. ${ }^{\mathrm{n}}$ Alfonso Bravo la licencia que solicita para la impresion del papel periodico titulado la Espigadera, pasandose antes al S. ${ }^{\text {or }} \mathrm{D} .{ }^{\mathrm{n}}$ Felipe Ribero, a fin de que nombre censor y disponga las reglas que juzgue oportunas para dicha impresión, conforme a lo acordado por punto general en el asunto (AHN, SC, Leg. 5555, n. 79).

El 3 de marzo de 1790, el licenciado don Felipe Ribero, Juez Interino de Imprentas, tal como se expone en la concesión de la licencia mencionada, suma al expediente de La Espigadera, a través de un escrito dirigido a los señores del Gobierno Cañada, Bendicho, Espinosa, Vallejo, Portero y Burriel, los nombres propuestos para censores - Rmo. P. Fr. Matias Villanuño, maestro general de la religión de San Benito, residente en San Martín de Madrid, y a don Juan Antonio Llorente, canónigo de Calahorra, residente en Madrid y Secretario de la Inquisición de Madrid - y cinco reglas a las que, según su experiencia, "conviene sujetar estas obras", que se resumen a continuación:

1. El autor o autores, en esta ocasión Alfonso Valentín Bravo, han de presentar el manuscrito limpio, con buena letra, foliado, "en tiempo que lo haya para reconocer sin priesa

${ }^{15}$ Sobre La Espigadera véase Paul-J. Guinard, La presse espagnole, 272-279; María Dolores Sáiz, Historia del periodismo en España, 173-174; Elisabel Larriba, "Une presse faite". 
el quaderno y subrrogar alguna oja, ó pliego en lugar de la que se repela".

2. Que no se presenten a la censura "mas pliegos ni ojas q las $\mathrm{q}^{\mathrm{e}}$ vasten para llenar el pliego o pliegos impresos prometidos al Publico". ${ }^{16}$

3. El manuscrito ha de presentarse con corrección y buena ortografía, y ha de ajustarse a las reglas impresas acordadas para el consejo en 12 de septiembre de 1788, aprobadas por su majestad el 2 de octubre del mismo año. ${ }^{17}$

4. Que se comunique la dirección de la oficina de imprenta y cualquier mudanza, pues se cree que las mudanzas suelen responder a "algún motivo $\mathrm{q}^{\mathrm{e}}$ debe llamar la atencion $\mathrm{y}$ vigilancia del juez de Ymprentas".

5. Los censores han de rubricar cada hoja o cuaderno del manuscrito, para remitir después al autor y este devolver la censura con la obra al juez de imprenta para obtener la licencia de impresión.

Las cinco reglas propuestas por el juez interino de imprentas, Felipe Ribero, se complementan con las siguientes seis disposiciones, recogidas en la ley dictada por Carlos III el 2 de octubre de 1788:

$1^{\mathrm{a}}$ Los autores y traductores de papeles periódicos, los presentarán, firmados por sí mismos, al Juez de imprentas solicitando licencia para su impresión.

$2^{\mathrm{a}}$ Presentado el papel se pasará al Censor que tuviere destinado, y no teniéndole, se le nombrará por el Juez de imprentas, quien podrá y deberá remitirlo á otro distinto cuando le parecie-

${ }^{16}$ Esta segunda regla busca impedir, entre otras cosas, que se impriman cuadernos que no hayan sido previamente aprobados por los censores.

${ }^{17}$ Se mencionan las reglas que deben observarse en los papeles periódicos y escritos, cuya impresión corra bajo la inspección del Juez de Imprenta, a las que estaban sujetos autores, traductores y censores, dictada por Carlos III en 2 de octubre de 1788, a consulta del Consejo de 12 de septiembre de ese mismo año. 
re y tuviere por conveniente, para evitar que se hagan dueños de la obra y perpétuos revisores de ella.

$3^{\mathrm{a}}$ Así los Censores, como los autores y traductores, cuidarán mucho de que en sus papeles y escritos no se pongan expresiones torpes, ni lúbricas, y tampoco sátiras de ninguna especie, ni áun [sic] de materias políticas, ni cosas que desacrediten las personas, los teatros é instrucción nacional, mucho ménos las que sean denigrativas al honor y estimacion de comunidades ó personas de todas clases, estados, dignidades ó empleos, absteniéndose de cualesquiera voces ó cláusulas que puedan interpretarse ó tener alusion directa contra el Gobierno y sus Magistrados, pena de que se procederá á imponerles ó exigirles las penas establecidas por las leyes.

$4^{\mathrm{a}}$ En las traducciones ó discursos de obras nacionales ó extranjeras que se insertasen en dichos papeles, se pondrá el nombre ó cita del autor, ó el libro de donde se haya sacado.

$5^{a}$ Hecha la impresión del papel periódico, se devolverá el original con un ejemplar impreso al Juzgado de imprenta, para que en todo tiempo se pueda reconocer si la impresión se hizo con el debido arreglo.

$6^{\mathrm{a}}$ Finalmente, los impresores no permitirán que en libros ó papeles se trate de asuntos resueltos por S. M., sus Ministros ó Tribunales, sin consulta ó permiso de S. M., ó de los mismos Tribunales y Ministros respectivos: ni tampoco de los que estén pendientes, pues de lo contrario, serán responsables el autor y Censores (Eguizábal, Apuntes para una historia, 44-45).

Por último, se recomienda observar con especial atención la disposición $5^{\mathrm{a}}$ de las citadas en las líneas antecedentes, proclive a ser olvidada con facilidad por los impresores.

El día 1 de julio de 1790 se aprueban las reglas e instrucciones formadas por el señor Juez de Imprentas para la publicación de La Espigadera y se nombra censor para ella a fray Diego Centeno, de la orden de San Agustín, conventual en San Felipe el Real de Madrid, y por sus ausencias probables, es nombrado su sustituto, don Domingo Ferrán, canónigo de San Isidoro el Real. 
A don Alfonso Valentín Bravo, que había presentado para examen y autorización un manuscrito compuesto por cuatro números, se le comunica - en escrito firmado por don Pedro Escolano de Arrieta, del Consejo de su majestad, secretario escribano de cámara más antiguo y del Gobierno- la resolución de su solicitud, autorizando la publicación de La Espigadera, junto con las reglas a seguir y el nombre de los censores, el 23 de septiembre de 1790.

La impresión de algunas obras y, en concreto, de Menipo litigante de Bartolomé Leonardo de Argensola contravienen, al menos, dos de las disposiciones referidas en la Ley de 2 de octubre de 1788 , en concreto la $3^{\mathrm{a}}$ y la $4^{\mathrm{a}}$, puesto que, por un lado, estamos ante un diálogo satírico que, de forma clara, censura los torticeros comportamientos y las actuaciones de jueces y abogados y, por otra, el nombre del autor no figura al comienzo o fin del diálogo — ni en ninguna otra parte de La Espigade$r a-\mathrm{y}$, de igual manera, se oculta la procedencia de esta obra de Argensola.

Alfonso Valentín Bravo verá llegar el fin de la publicación periódica a causa de una Real Resolución, fechada el 24 de febrero de 1791 y auto del Consejo de 12 de abril del mismo año, que obligaba a la suspensión de todos los papeles periódicos (Novísima 1805-1808, T. IV, Lib. VIII, Tít. XVII, Ley V, 151-152):

Con motivo de advertirse en los Diarios y papeles públicos que salen periódicamente, haber muchas especies perjudiciales; cesen de todo punto, quedando solamente el Diario de Madrid de pérdidas y hallazgos, ciñéndose a los hechos, y sin que en él se puedan poner versos, ni otras especies políticas de cualquiera clase. Y en su conseqüencia no se permita la continuación á los autores del Memorial Literario, la Espigadera; y Correo de Madrid. ${ }^{18}$

${ }^{18}$ Los únicos diarios que no se ven afectados por esta Real Resolución son, según indica María Dolores Sáiz (Historia del periodismo en España, 95), el "Diario de 
Desde 1790 a 1791 el editor de La Espigadera ${ }^{19}$ dará a la imprenta un total de 17 números distribuidos en 2 tomos, el primero formado por 12 y el segundo por los 5 fascículos restantes. A esto tenemos que añadir el "Prospecto de esta obra" en el que el editor justifica la necesidad de una nueva publicación periódica, indica la forma de suscripción, el número aproximado de pliegos que constituirán los fascículos, además de los compromisos que adquiere con los futuros lectores. Este "Prospecto" está compuesto por veintiuna páginas y es de gran interés para comprender los rasgos y contenidos que constituyen la publicación. Por último, es preciso sumar al final del primer tomo, las páginas en las que se imprime el índice de este y la lista de suscriptores (La Espigadera 1790-1791). ${ }^{20}$

Madrid y los oficiales: el Mercurio y la Gaceta". El autor de La Espigadera, Alfonso Valentín Bravo, así figura en el expediente ya citado (AHN, SC, Leg. 5555, n. 79), insistirá ante las autoridades, a pesar de la aprobada Real Resolución de prohibición para la impresión de papeles periódicos, en continuar con su publicación, sin obtener una respuesta positiva a sus peticiones. Es muy comprensible su persistencia ante las autoridades para proseguir con la impresión de la publicación, cuando se tiene en cuenta que algunos editores de papeles periódicos de financiación privada tuvieron una reacción de protesta frente a esta Real Resolución, ya que suponía para ellos una situación económica difícil, en algunos casos insostenible, que les conducía a la ruina. En esta circunstancia, entre otros, se encontraban: Cristóbal Cladera, editor del El Espíritu de los Mejores Diarios; Luciano Francisco Comella, autor del Diario de las Musas; Joaquín Ezquerra, fundador del Memorial Literario; Antonio Valladares y Sotomayor, responsable del Semanario Erudito, y Alfonso Valentín Bravo, editor de La Espigadera.

${ }^{19}$ Teniendo en cuenta los pormenores extractados del expediente de la publicación ya relacionados en líneas anteriores (AHN, SC, Leg. 5555, n. 79), considero que el primer número pudo salir alrededor del mes de octubre, suposición que además es avalada por hallar en él una "Carta irónica de un extranjero a un paisano...." fechada el 20 de septiembre de 1790; mientras que el último, el número 17, tiene que estar cercano a la fecha de la Real Resolución citada (24 de febrero de 1791), ya que en el fascículo 15 se imprime una "Carta contra varias décimas de don Lucas Alemán, insertas en el Diario de las Musas..." que fue depositada en la Librería de Luis Mafeo, sita en la Carrera de San Jerónimo, el día 20 de enero de 1791. El nombre de Alfonso Valentín Bravo no figura en ninguna de sus páginas impresas, por ello se toma del expediente de La Espigadera, custodiado en el Archivo Histórico Nacional de Madrid (SC, Leg. 5555, n. 79) en el que figura, entre otros documentos, la solicitud de licencia para su impresión, realizada por el dicho Alfonso Valentín Bravo.

${ }^{20}$ El "Prospecto" se imprime con paginación independiente (3-21) así como el 
La información extraída de las páginas preliminares y finales del primer tomo permite obtener un perfil de la publicación y de sus lectores, y, a su vez, ayuda a interpretar el contexto en el cual se difunde impreso el diálogo satírico contra los malos abogados y jueces, hasta entonces inédito, de Bartolomé Leonardo de Argensola y, quizá, proponer el nombre del posible o posibles responsables de su impresión en esta publicación. No olvidemos que en este período la inclusión de sátiras o papeles de crítica social son determinantes en el éxito de las reformas sociales que pretenden llevarse a cabo a fines del siglo xvIII y que culminan en la siguiente centuria, por tanto, la publicación de textos como el de Argensola podría responder a este objetivo. ${ }^{21}$ Además en este aspecto, el de la reforma social, se cifra parte de la amplia difusión que alcanzan los papeles periódicos y sus reimpresiones. El mejor ejemplo que constata este hecho lo hallamos en El Censor de Luis García del Cañuelo y de Luis Pereria (Sáiz, Historia del periodismo en España, 183-202).

índice y la lista de suscriptores anexa al primer tomo (1-16). El ejemplar consultado conserva el "Prospecto", el tomo I, el índice, la lista de suscriptores y el tomo II encuadernados en un solo volumen (BNE: R/7167).

${ }^{21}$ Lía Schwartz estudia los tipos representados en la sátira del Siglo de Oro y afirma que "en el universo de representación de la sátira áurea, en todas sus variantes, seguía siendo blanco de la crítica satírica un gran número de tipos sociales y morales que provenía de los textos fundacionales del género [...]. Así puede explicarse, por ejemplo, la reiterada crítica de médicos y abogados que encontramos en la sátira áurea. No podían faltar, evidentemente, en la obra de Bartolomé" ("Bartolomé Leonardo de Argensola", 61-62). Efectivamente, no faltan las censuras a los letrados en la obra del aragonés, pues junto a Menipo y un buen racimo de poemas, también dedica a este asunto otro diálogo satírico, Dédalo. En ambos diálogos, nos dice Schwartz, "examinó el tema de la justicia en sus dos dimensiones. Por un lado, en el Dédalo denunció la corrupción de la justicia real [...]. En cambio, en el diálogo Menipo litigante, planteaba el comportamiento corrupto de los jueces que dirimían disputas civiles y criminales, y de sus ministros [...]. En ambas sátiras se exponía la paradoja [siguiente:] la multiplicación de los letrados sólo había conseguido, paradójicamente, que hubiera menos justicia en la tierra. La acusación caía sobre los abogados y sobre los jueces, de los que decían que tergiversaban la virtud de iustitia en vanos pleitos y demandas" ("Bartolomé Leonardo de Argensola", 64). Este asunto, la denuncia de los que "tergiversan la virtud de iustitia", sin duda respondía a los fines que se proponían los papeles periódicos del siglo XVIII. 
En líneas anteriores, he mencionado la importancia del "Prospecto", pues ayuda a entender los objetivos que se fija el editor y los compromisos adquiridos por él ante los potenciales lectores, así como la heterogeneidad de los contenidos publicados en la obra periódica. El autor del "Prospecto"22 justifica la publicación de una nueva obra periódica, después de una larga disertación, para "restablecer el crédito de los Diarios", que se inicia con la siguiente afirmación:

Es constante que una Nacion no puede ser sábia, en tanto que permanezca en la errada inteligencia de que un hombre es capáz de formarse sólidadmente en la parte literaria sólo con el manejo de las Bibliotecas, los Beyerlinks, las Polianteas, y singularísimamente con la lectura de los varios Periódicos, que sucesivamente han ido saliendo á luz en todas las Naciones cultas de Europa.

Y, a la vez que da razones para la aparición de una nueva publicación, desgrana los objetivos marcados:

Nuestro fin principal es desengañar al Público, rectificar las nociones comunes, dar justa idéa del mérito de estos Periódicos [...], los varios intereses que pueden percibir de su lectura los diferentes miembros de una República [...], resolver si estos papeles esencialmente no son capaces de producir sino una instruccion efimera, ó si esta puede ser de consecuencia transcendental á la felicidad pública.

Por ello afirma, en estas mismas páginas, que "los editores están dispuestos a expresar sin equivocación sus nombres y apellidos", pero el de La Espigadera, Alfonso Valentín Bravo, escamotea su nombre a los ojos de sus suscriptores y lectores;

${ }^{22}$ En un principio tenemos que pensar que el autor es el editor de La Espigadera, mas François Lopez cree posible que estas páginas hayan surgido de la pluma de Juan Pablo Forner; véase López, Juan Pablo Forner y la crisis, 479, n. 80. 
aunque lo conocemos gracias a la documentación conservada en el expediente de la publicación (AHN, SC, Leg. 5555, n. 79).

La finalidad recogida en estas páginas no concuerda con exactitud con la dicha en la solicitud de licencia presentada al Juez de Imprentas, donde se afirma:

Que teniendo una colección de opúsculos ia propios ia de otros autores conocidos, i de aquellos que mas bien admitidos están en el público, determino por instrucción de este, porque no quedaran sepultados como tantos otros escritos utiles, por contribuir a desvanecer la calumnia estrangera de que los españoles no escriven cosas arregladas i de buen gusto (AHN, SC, Leg. 5555, n. 79).

En busca de la educación a la que tiene derecho el público, Alfonso Valentín Bravo se compromete a ofrecer en las páginas de La Espigadera papeles curiosos y noticias instructivas sobre asuntos diversos: "alguna idéa del teatro, examinando qual vez alguna pieza dramática; se formará juicio de tal qual Obra antigua ó moderna [...] con el fin de enderezar á los jovenes lectores por la via del buen gusto [...]; se extractarán algunos Concilios Nacionales antiguos, expresando varias particularidades que en ellos ocurrieron, sacadas de los manuscritos mas apreciables"; se incluirán extractos de las vidas de algunos reyes de España, con presencia de varios códices inéditos de los que guardan nuestras bibliotecas; se traducirán papeles y diarios extranjeros, especialmente las Efemérides de Roma ${ }^{23}$ tanto las noticias políticas como literarias tendrán también su lugar en esta publicación; se insertarán discursos selectos, anécdotas curiosas de todo tipo; se informará de sucesos acaecidos en las provincias del reino, "y finalmente se permite á qualquier Subs-

\footnotetext{
${ }^{23}$ Efemérides de Roma es el título de una gaceta italiana en la que se da aviso de libros publicados en Italia o fuera de ella, nuevos descubrimientos o invenciones, otras noticias de las artes y literatura, etcétera.
} 
criptor ó apasionado pueda insertar todo lo que guste, bien sean noticias particulares del Reyno, ó bien discursos ó críticas de todas clases", siempre que no contengan extravagancias, maledicencia, mal gusto, y lo que no es menos importante, "que esté arreglado á las disposiciones y reglas dadas por el Gobierno", más intentando que lo aparecido aquí no se repita en ningún otro periódico nacional $\mathrm{y}$, al tiempo, que las "especies sean selectas". ${ }^{24}$

Esto es lo que se refiere al contenido de la obra, sobre aspectos más formales (periodicidad, extensión, etc.) se afirma en este mismo "Prospecto" que no se comprometen a un número determinado de pliegos por fascículo, aunque se afirma que no bajará de dos y, si los sobrepasase por exigirlo la extensión del texto y no poder cortarlo para continuarlo en el siguiente número, se procurará no cargar más el precio, siempre que el "exceso no sea notable"; 25 tampoco se pretende establecer un orden invariable para las materias, ni publicar la obra "en un periodo regular y constante" con día fijo. ${ }^{26}$ A continuación se detalla el precio de cada número y de la suscripción por los doce primeros ("Prospecto", La Espigadera, 1790, 19-21).

Al examinar con detalle la publicación, comprobamos que más o menos se cumple con los compromisos adquiridos en el folleto descrito, también apreciamos que son publicadas las cartas y los opúsculos remitidos por los suscriptores, que se traducen y extractan textos procedentes de las Efemérides de Roma, que las vidas de algunos reyes de España están presentes, que la crítica teatral o escritos sobre teatro encuentran su

\footnotetext{
${ }^{24}$ En estos párrafos resumo las páginas 6-18 del "Prospecto" (La Espigadera 1790-1791).

${ }^{25}$ Se trata de una publicación en $8^{\circ}$, por lo que se garantiza un mínimo de 16 páginas por número.

${ }^{26}$ En la solicitud de licencia (AHN, SC, Leg. 5555, n. 79) Alfonso Valentín Bravo manifiesta su intención de imprimir uno o dos números a la semana y, a pesar de no comprometerse a una periodicidad, consigue dotar a la publicación de regularidad, dando a los lectores un fascículo semanalmente.
} 
sitio en las páginas de la publicación; pero eso sí, la mayor parte de lo impreso en los 17 números no tiene mención de autoría, de tal manera que, ocultos en el anonimato, se deslizan, por ejemplo, escritos de Juan Pablo Forner ${ }^{27}$ o el de Bartolomé Leonardo de Argensola que nos ocupa. ${ }^{28}$

También observamos que los doce primeros números no superan las dieciséis o veinte hojas, sin producirse desperdicio de papel en ninguno de ellos, únicamente en el número diez queda una hoja en blanco por haberse añadido una nota sobre la renovación de la suscripción.

Por último, destacar que entre los suscriptores figuran nombres de gran relevancia en la vida política, cultural, etc. del momento, como el conde de Floridablanca, Secretario del Despacho de Estado y de Gracia y Justicia; el conde de Campomanes, Secretario de la Suprema Junta de Estado; Eugenio Llaguno y Amírola, Secretario de la Suprema Junta de Estado; Manuel de Bustamante, Oficial del Juzgado de Imprentas; Joaquín de Ezquerra, periodista del Memorial Literario; Antonio Valladares y Sotomayor, editor del Semanario Erudito; ${ }^{29}$ Juan Sempere y Guarinos, Fiscal de la Real Chancillería de Granada, quien publicó el conocido Ensayo de una biblioteca española de los mejores escritores del reynado de Carlos III, ${ }^{30}$ y Juan Pablo Forner, Fiscal de la Real Audiencia de Sevilla, asiduo colaborador de La Espigadera, autor destacado del siglo XVIII.

${ }^{27}$ Sin lugar a duda, el Discurso imparcial y verdadero sobre el estado actual del teatro español, publicado en el n. 1, se debe a la pluma de Forner. Vid. Juan Pablo Forner, Exequias de la lengua castellana, LXXII, 210, nota 396 y 407-417; también Rosalía Fernández Cabezón, "Forner, crítico teatral", 439-458.

${ }^{28}$ Como ya dije, esta tendencia al anonimato contraviene una de las disposiciones dictadas por el Gobierno, a pesar de afirmar Valentín Bravo que los discursos, críticas, etc. se ajustan a disposiciones y reglas gubernamentales.

${ }^{29}$ Tanto el Memorial literario instructivo y curioso de la Corte de Madrid como el Semanario erudito de obras críticas, morales, instructivas, políticas, etc. se comienzan a publicar unos años antes que La Espigadera, en 1787, y cesan en 1791, al igual que el resto de diarios y papeles periódicos.

${ }^{30}$ Esta obra fue impresa en Madrid, Imprenta Real, 1785-1789. 
Lamentablemente, el segundo tomo carece de índice y de lista de suscriptores por haberse interrumpido la publicación de la obra de forma abrupta.

\section{Menipo litigante publicado en La Espigadera}

Teniendo en cuenta todos estos aspectos señalados, veamos qué ocurre con el texto de Menipo impreso en La Espigadera. Como indiqué, se encuentra este diálogo en el número 7 de la obra periódica, tal vez correspondiente a la segunda o tercera semana del mes de noviembre de 1790, en las páginas 209-236. Con el diálogo de Leonardo de Argensola se abre el fascículo. No hay referencia al título por el que se le conoce, Menipo o Menipo litigante, ni tampoco se le asigna uno nuevo, sino que es introducido con un largo encabezamiento: "Para comprobar que siempre se ha declamado contra los que tuercen el verdadero sentido y espíritu de las leyes", al que le sigue una breve nota que hace referencia a cómo ha llegado hasta el editor de la obra periódica dieciochesca la sátira lucianesca de Argensola: "insertamos, según se nos ha remitido, el siguiente DiÁlogo" ( $L a$ Espigadera 1790-1791, n. 7, 209). Por tanto, esta obra del rector de Villahermosa llega a La Espigadera a través de alguno de sus suscriptores o de sus colaboradores, hábito muy extendido en las publicaciones de la época. Asimismo, el ocultar el nombre del autor no tiene que extrañarnos, pues es costumbre tanto en la prensa de este siglo como en la del siguiente valerse del anonimato, ya que el responsable de todo publicado es el editor - como se dice en el "Prospecto" ya citado-, conocido por las autoridades y considerado por ellas autor si, como en este caso, no consta, y así será requisito imprescindible que figure su nombre tanto en la solicitud, como en la concesión de la licencia, aunque no aparezca luego impreso en ninguna de las páginas de la publicación periódica. 
La pregunta que en este punto surge versa en torno a quién pudo disponer de un manuscrito de esta obra y que, a su vez, tuviese relación o fuese suscriptor o colaborador de La Espigadera. Los pasos dados en este sentido apuntan hacia dos sobresalientes eruditos de la época: Juan Pablo Forner y Eugenio Llaguno y Amírola.

La admiración que Juan Pablo Forner sentía por la obra de los hermanos Argensola es de sobra conocida y se hace presente en varios de sus escritos. Recordemos, a modo de ejemplo, los versos de la Sátira contra los vicios introducidos en la poesía castellana en los que destaca a Bartolomé como magnífico imitador de Juvenal:

Ni se hallará tal necio, que lastime, que acicale el menor de los Leonardos la cruda espada que el de Aquino esgrime.

(Forner, Sátira contra los vicios, vv. 709-711)

También son varias las alusiones a los aragoneses que podemos leer en la Exequias de la lengua castellana, en donde declara dicha admiración:

Ante los dos Leonardos

pronunciaré, encogido, palabras con que entiendan cuánto a los dos admiro.

(Forner, Exequias de la lengua castellana, 50)

En otro momento, es la maestría en el cultivo de la sátira el motivo de la alusión (en este caso no precisa a cuál de los dos hermanos se refiere): “¿Abandonáis todas estas ocupaciones inútiles y os metéis a satírico? Juvenal os presta su cólera, su donaire Horacio y Argensola su magisterio" (61). Y, por último, en otro lugar se alaba la poesía de los dos Leonardos: 
"Los dos Argensolas juntaron con talento admirable las galas de una poesía varonil a la severidad de la moral" (145).

Junto a esto, otro elemento que hace pensar en Forner como probable remitente de Menipo litigante es el hecho de ser este un diálogo en el que se trata de los malos abogados y jueces - como ya dijo Pellicer-, desde el cual el autor, Bartolomé Leonardo de Argensola, desarrolla la sátira siguiendo a uno de los modelos clásicos, Luciano. ${ }^{31} \mathrm{El}$ tema no le es ajeno al extremeño, pues cursó estudios de abogacía que le llevaron al cargo de Fiscal de la Real Audiencia de Sevilla en el año 1790. ${ }^{32}$ Y el género satírico, en concreto la sátira menipea, le interesó sobremanera - recordemos el título completo con el que ya se publica por vez primera las Exequias y que las sucesivas ediciones han mantenido: Exequias de la lengua castellana. Sátira menipea - ${ }^{33} \mathrm{y}$ a ella dedicará innumerables páginas.

Por último, tanto Juan Pablo Forner como Eugenio Llaguno poseyeron manuscritos de los hermanos Leonardo de Argensola que cedieron para la preparación de los tomos dedicados a sus obras en la Colección de poetas castellanos, publicada por Ramón Fernández. ${ }^{34}$ Podemos estar seguros de ello por el

${ }^{31}$ Véanse los trabajos de Otis H. Green, "Notes on the Lucianesque Dialogues", 275-293; Lía Schwartz "Bartolomé Leonardo de Argensola”, vol. 1, 75-93.

${ }^{32}$ En la "Lista de suscriptores", inmediatamente después de cada nombre, figura el cargo que en ese momento ocupaba el suscriptor, el de Fiscal de la Real Audiencia de Sevilla es ya reseñado en la lista después del nombre de Juan Pablo Forner ( $\mathrm{La}$ Espigadera 1790-1791, t. 1, 14).

${ }^{33}$ La primera edición de esta obra corresponde a Juan Pablo Forner, Exequias de la lengua castellana. Sátira menipea, dispuesta por Leopoldo A. de Cueto, Madrid, Imprenta de M. Rivadeneyra, 1871 (Biblioteca de Autores Españoles, vol. 63). Sobre este asunto véase López, Juan Pablo Forner y la crisis; Carbonell, "Las 'Exequias de la lengua castellana'”, n. 2, quien señala que "únicamente el Ms. 6795 de la Biblioteca Nacional presenta el rótulo 'Sáti[r]a Varroniana', mientras que el Ms. 122 de la Real Academia, que responde a la primera redacción, inacabada, de la obra, y de gran importancia para comprender el designio inicial de Forner al concebirla y esbozarla, en un contexto bastante alejado del que presidirá su redacción definitiva, sólo comprende el título de la obra, sin subtitular".

${ }^{34}$ Se trata de la edición Rimas del doctor Bartolomé Leonardo de Argensola, por 
irrefutable testimonio que ofrece en carta Forner, del 13 de febrero de 1790, para la resolución de un conflicto, entre Ramón Fernández y Pedro Estala, sobre la autoría de la traducción del Origen de los descubrimientos atribuidos a los Modernos: ${ }^{35}$

Estala formada una especie de compañía con Dn. Ramón Fernández, vecino de esta Corte, para la reimpresión de nuestros buenos Poetas, supe se había valido déste para efectuar la impresión de la expresada Traducción, por ser dicho Fernández el que agenciaba y costeaba las impresiones de los Poetas en cuyos Prólogos, correcciones, adiciones y variantes trabajaba Dn. Pedro Estala, para lo qual le sumministró algunos Códices el Sor. Dn. Eugenio Llaguno, y yo le proporcioné también varios ms. relativos a Bartolomé de Argensola y a Fernando de Herrera (apud Andioc, "Ramón Fernández”, 18).

Llaguno puso a disposición de Ramón Fernández un manuscrito - con toda seguridad el mismo al que hace referencia Forner en el documento citado en líneas precedentes - con poesías de Lupercio y así se hace constar en la edición de las Rimas de los hermanos:

Pero porque no se crea que nuestro juicio es errado, ó que no nos hemos querido tomar el trabajo de buscar y registrar los manuscritos, pondremos aquí varias piezas, para demostrar que ó son supuestas, ó no son comparables á las mas inferiores de las impresas. Esto se puede afirmar sin temeridad de todas quantas hemos visto; y daríamos muchas gracias al que imprimiese otras piezas inéditas, probando, no con elogios vagos, sino con un exámen crítico, que son comparables ó superiores

don Ramón Fernández, Madrid, Imprenta Real, 1786, ts. II y III (el t. I se dedica a las poesías de Lupercio), reimpresas en los años 1804-1805 (cito por esta reimpresión).

${ }^{35}$ Respecto a la disputa entre Fernández y Estala véase el expediente conservado en el AHN, SC, Leg. 5544, n. 97 y el artículo de René Andioc, "Ramón Fernández", $18-19$. 
á las impresas, que tanto hemos recomendado. Primeramente insertamos doce sonetos, que juzgamos son obras legítimas de Lupercio, no sólo por hallarse en un manuscrito muy completo de todas sus poesías, que se ha servido comunicarnos el Señor Don Eugenio Llaguno y Amírola, primer Oficial de la Secretaría de Estado, sino principalmente por su estilo; pero qualquiera que los exâmine con imparcialidad, hallará la gran diferen// cia que hay de ellos al mas inferior de los impresores; y se persuadirá que no sin razón los omitió el primer editor (Leonardo de Argensola, Rimas, t. III, 5-6).

No es audaz considerar, a tenor de lo expuesto, la posibilidad de que en cualesquiera de los manuscritos que se han mencionado, propiedad de Forner uno y de Llaguno el otro, además de poesías de los aragoneses, hubiese una copia del diálogo $\mathrm{Me}$ nipo litigante escrito por el menor de los hermanos Argensola, por lo que podría ser, bien Juan Pablo Forner o bien Eugenio Llaguno y Amírola, el suscriptor anónimo remitente de Menipo litigante impreso en La Espigadera. Como ya dije, el texto proporcionado para esta publicación periódica está reformulado, amputado y excepcionalmente ampliado en algunos pasajes, alejándose así de las cinco copias manuscritas hasta ahora conocidas (véase el Apéndice).

\section{Conclusión}

Menipo litigante, considerado inédito hasta la edición del Conde de la Viñaza en el año 1887, fue impreso por vez primera en un papel periódico con intereses literarios. Este impreso ha sido ignorado hasta este momento por editores y estudiosos de los diálogos de Bartolomé Leonardo de Argensola. Las diferencias que se aprecian entre este testimonio y los otros conocidos son notables, razón esta que, a mi parecer, justifica la edición del 
texto transmitido en La Espigadera independientemente del derivado de la tradición manuscrita, a la que hay que sumar dos manuscritos, que si bien han sido tenidos en cuenta a la hora de editar las rimas, se deberán colacionar para la edición del diálogo. 


\section{APÉNDICE*}

\section{EJEMPLO 1}

$\begin{array}{cc}\text { Menipo litigante } & \text { Menipo litigante } \\ \text { (Tradición manuscrita) } & (\text { La Espigadera })\end{array}$

Menipo. - Digo que de to- Menipo. - Digo que de todas das las partes, o a lo menos de partes, principalmente de las las más vecinas de Atenas, se más vecinas a Atenas, se apareaparecieron parientes míos, los cieron parientes míos que por dicuales por diversas vías pusie- versas vías pusieron en el Senaron demanda en el Senado a toda do demanda a toda mi hacienda. mi hacienda. Tenía de su parte A cada cual favorecían ciertos cada cual ciertos jurisconsultos jueces y otros ministros que y otros ministros que ejecutaban ejecutaban todo lo que aquellos todo lo que estos ordenaban y, ordenaban y, como yo sabía que como yo sabía que aquella ha- aquella hacienda había sido de cienda había sido de mi padre y mi padre y que él la heredó del él la heredó del suyo y que las le- suyo y que las leyes de naturaleyes de naturaleza y los vínculos de los primeros fundadores me hacían sucesor forzoso en ella, burlábame del pleito y tenía por locos a los actores. Mostráronse ciertos testamentos de los predecesores, en los cuales se hallaban instituidos mis agüelos, za me hacían sucesor forzoso en ella, me burlaba del pleito y tenía por locos a los actores, y solía decir entre mí: "Estos, sin duda, carecen de todo discurso, porque se piensan que mi hacienda no es mía, aunque es credulidad terrible, son locos. Mas, si no con-

\footnotetext{
* Para entender el proceso de manipulación que sufrió el texto de Menipo litigante impreso en La Espigadera coloco ambos enfrentados, de un lado el texto según que se conserva en la tradición manuscrita y, de otro, el texto de La Espigadera publicado en el año 1790. Uso subrayado en el texto manuscrito para señalar lo que se suprime en el impreso. Empleo cursiva en el texto impreso para indicar lo que no está en la tradición manuscrita. Por último, utilizo negrita para resaltar las modificaciones en la redacción. No se marcan los cambios de orden sintáctico.
} 
mis padres y yo y nuestra línea y descendientes; pero tales fueron las interpretaciones que aquellos jurisconsultos les dieron que, leyéndolas yo mismo alguna vez, venía a juzgarme por injusto posesor, aunque después pensaba que no era posible que la mentira prevaleciese. Los jurisconsultos, que yo tenía conducidos para defenderme se dieron tal maña que respondieron a sus calumnias de manera que me aseguraba dellas. $\underline{Y}$ era cosa notable, ¡oh, Arsitas!, ver con qué osadía afirmaban que, donde los disponientes dijeron que querían que sucediésemos Nearco, mi padre, y yo $\mathbf{y}$ todos nuestros descendientes, se había de entender por sucesión voluntaria, $\mathrm{y}$ que no por las palabras se nos adquiría título alguno, sino solamente el que atribuye el derecho común. Todo para fundar mi exclusión y anular el fideicomiso, para que mis bienes, como libres, pudiesen quedar obligados a las deudas que sobre ellos contrajo mi agüelo. ¡Si tú vieras con cuántos argumentos enflaquecía la voluntad escrita, trocando el sentido a las palabras, derramando tinieblas y significaciones sobre ellas, dudando aun tentos con esto, dan a entender que es suya, deseo ver en que lo fundan»]. Mostráronse ciertos instrumentos públicos y testamentos de mis predecesores, en que se hallaban instituidos herederos mis padres y yo y la línea de nuestros descendientes; mas tales fueron las interpretaciones que los jueces les dieron que, leyéndolas yo mismo, me venía a juzgar por injusto poseedor, aunque después pensaba que no era posible prevaleciese la mentira. Los letrados que pagué para que me defendiesen, se dieron tal maña y respondieron a sus calumnias de manera que me aseguraba de ellas. Era cosa notable, ¡oh, Arsita!, ver la osadía con que afirmaban que, donde los testadores dijeron que sucediésemos mi padre, Nearco, y yo con todos nuestros descendientes por sucesión voluntaria, que no por las palabras se nos adquiere título alguno, sino solamente el que da el derecho común, queriendo con gran aparato de argumentos enflaquecer la verdad escrita, trocando el sentido de las palabras, derramando sobre ellas tinieblas y diversidad de significaciones, dudando 
del sonido vulgar que hiere en los oídos y del conceto, que por él se declara al juicio y consentimiento universal de la patria, violando toda la oración y finalmente haciendo que las palabras declarasen la mente del que las dijo al contrario de como la quiso declarar! $\underline{Y}$ mira tu: ¿cómo sacarás derecha la línea si doblas en forma de arco la regla por donde ha de andar arrimado el plomo o la pluma que la señala? Y, pues el juez en la república, para la destribución de la justicia derecha, es lo mismo que la regla para las líneas, dime tu: ¿qué tales saldrán sus decretos siendo formados por ánimo inclinado $\mathrm{y}$ torcido?

\section{EJEMPLO 2}

Menipo litigante

(Tradición manuscrita)

Menipo. - ¡Oh, Arsitas! ¡ $\mathrm{Si}$

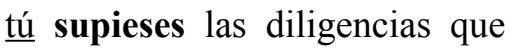
hice! Una te contaré, pues estamos solos, que te parecerá increíble aunque no se me logró. Sabe que, como yo vi que ponían toda la dificultad del pleito en atinar del sentido vulgar que hiere los oídos y del concepto que por él se declara, y del juicio y consentimiento universal de la patria, violando toda razón con sus alegatos y finalmente haciendo que las dijo al contrario de como él quiso significarla. Mira: ¿cómo sacarás derecha la línea si tuerces y doblas como arco la regla por donde ha de andar arrimado el plomo o pluma que la señala? Y pues, el juez, para la distribución de la justicia, es lo mismo que la regla para las líneas, dime ¿qué tales saldrán sus decretos siendo formados por ánimo inclinado?
Menipo litigante (La Espigadera)
Menipo. - ¡Oh, Arsita! ¡Si supieras las diligencias que hice! Una te diré, pues estamos solos, que te parecerá increíble, aunque no se me logró. Sabe que como vi que ponían toda la dificultad del pleito en atinar lo que Alitias, 
lo que Alitias, mi bisabuelo, había querido decir en las palabras de su testamento cuando nos instituyó por herederos a Dulipo, su hijo, a Nearco, mi padre, a mí y a nuestros descendientes, aunque él claramente dijo que quería que sucediésemos todos con efeto, determiné de bajar, y bajé de hecho, a la región escura de Plutón que está en el centro de la tierra y la llaman infierno, a donde están las almas o manes de los difuntos, para preguntar a la de mi bisabuelo la verdad.

Arsitas. - ¿Al infierno?

Menipo. - Sí, al infierno.

Arsitas. - ¡Oh, Júpiter!, autor y movedor de las obras magnánimas, pues no lo será menor el creer esta que el haberla obrado Menipo. Ayúdame tú a reducirme, a darle crédito, que yo a solas no puedo, ni oso y, por decirlo más claro, no quiero.

Menipo. - Luego tampoco creerás que bajaron allá Úlises, ni Eneas, Teseo y los otros héroes celebrados.

Arsitas. - La fama misma que trata de ellos te los dio por compañeros en esta empresa y yo días ha que lo había oído, pero no pensé que lo confesabas, mi abuelo, había querido decir en las palabras de su testamento cuando instituyó por herederos a Nearco, mi padre, a mí y a nuestros descendientes, aunque él claramente dijo que quería sucediésemos en efecto, determiné bajar, y bajé de hecho, a la obscura región que está en el centro de la tierra y la llaman infierno, donde están las almas o manes de los difuntos, para preguntar a la de mi abuelo la verdad.

Arsita. - ¿Y cómo supiste el camino? 
porque te tuve siempre por más verdadero.

Menipo. - Digo que bajé allá de la misma manera que esos excelentes héroes con estos pies y en el mismo sujeto que te habla. Demás que, pues crees que subí al cielo, ¿por qué dificultas mi bajada al infierno?

Arsitas. - ¿Y cómo sabes tú que creo tu subida al cielo? Menipo. - A la fe, Arsitas, todo lo he andado, y no tanto debes admirarte desto como de lo poco que me aprovechó, y reconocer en este ejemplo cuánto es más vencer la obstinación de un juez humano que la de tan increíbles jornadas.

Arsitas. - ¿Y cómo supiste el camino?

\section{REFERENCIAS}

ANDIOC, René, "Ramón Fernández siempre será Ramón Fernández", Ínsula, 504, 1988, 18-19.

ArCo y Garay, Ricardo del, La erudición española en el siglo XVII y el cronista de Aragón Andrés de Ustarroz, Madrid, Consejo Superior de Investigaciones Científicas, 1950.

AHN: Archivo Histórico Nacional, Sección Consejos, Legajo 5544, n. 97.

AHN: Archivo Histórico Nacional, Sección Consejos, Legajo 5555, n. 79 . 
Blecua, José Manuel, "Manuscritos e impresos utilizados" en, $R i$ mas de Lupercio y Bartolomé Leonardo de Argensola, vol. 1, Zaragoza, Consejo Superior de Investigaciones Científicas, 1950, LX-XCIII.

Carbonell, María Cristina, "Las 'Exequias de la lengua castellana' de Juan Pablo Forner, 'sátira menipea'", Anales de la Literatura Española, 8-1, 1992, 37-52. <http://www.cervantesvirtual.com/ servlet/SirveObras/12826060886957193087402/p0000001. htm> [fecha de consulta: febrero, 2009].

EguizÁBal, José Eugenio de, Apuntes para una historia de la legislación española sobre imprenta, desde el año de 1480 al presente, Madrid, Imprenta de la Revista de Legislación (ejemplar de la BNE: 9/255995), 1873.

La Espigadera (1790-1791) [editor Alfonso Valentín Bravo], Madrid, Imprenta de Blas Román, nn.1-17 (ejemplar de la BNE: R/7167). Esteve Barba, Francisco, Catálogo de la colección de manuscritos Borbón-Lorenzana, Madrid, Imprenta Góngora, 1942.

FERNÁNDEZ CABEZÓn, Rosalía, "Forner, crítico teatral de La Espigadera", RevistadeEstudios Extremeños, 57:2,2001,439-458.<http:// www.dip-badajoz.es/publicaciones/reex/rcex_2_2001/estudios_02_rcex_2_2001.pdf> [fecha de consulta: febrero, 2009]. Forner, Juan Pablo, Sátira contra los vicios introducidos en la poesía castellana premiada por la Real Academia Española, en Junta que celebró el día 15 de Octubre de 1782, Madrid, Joaquín Ibarra, 1782 (ejemplar de la BNE: VC/21641/10). Edición digitalizada: <http://www.cervantesvirtual.com/servlet/SirveObras/ 01604963658926056322257/p0000001.htm\#1> [fecha de consulta: febrero, 2009].

ForNer, Juan Pablo, Exequias de la lengua castellana. Sátira menipea, dispuesta por Leopoldo A. de Cueto, Madrid, Imprenta de M. Rivadeneyra, 1871 (Biblioteca de Autores Españoles, vol. 63).

Forner, Juan Pablo, Exequias de la lengua castellana. Sátira menipea, ed. José Jurado, Madrid, Consejo Superior de Investigaciones Científicas, 2000.

Foulchè-Delbosc, Raymond, "Pour une édition des Argensolas", $R e$ vue Hispanique, XLVIII, 113, 1920, 318-319. 
Green, Otis H., "Notes on the Lucianesque Dialogues of Bartolomé Leonardo de Argensola", Hispanic Review, 3, 1935, 275-293.

GuINARD, Paul-J., La presse espagnole de 1731 a 1791. Formation et signification d'un genre, Paris, Centre de Recherches Hispaniques, Institut d'Etudes Hispanique.

Inventario general de manuscritos de la Biblioteca Nacional (19701987), Madrid, Ministerio de Cultura, Dirección General del Libro y Bibliotecas, vols. IX-XI, 1973.

Lamarca Langa, Genaro, "Memorias literarias de Aragón de Félix Latassa. Estudio y descripción”, Turiaso, XV, 1999, 127-173. Edición digitalizada: <http://www.dpz.es/turismoNuevo/multimedia/no_editados_patronato/varios/turiaso/TuriasoXV-5.pdf $>$ [fecha de consulta: febrero, 2009].

Latassa y Ortín, Félix de, Biblioteca antigua de los escritores aragoneses que florecieron desde la venida de Cristo hasta el año 1500, Zaragoza, en la Oficina de Medardo Heras, 2 vols., 1796 (ejemplar de la BNE: INV 013(460) ARA 2).

Latassa y Ortín, Félix de, Biblioteca nueva de los escritores aragoneses que florecieron desde el año de 1600 hasta 1640, Pamplona, en la oficina de Joaquín de Domingo, calle del Carmen Calzado, 6 ts. (t. II, 1799) (ejemplar de la BNE: INV 013(460) ARA 5), 1798-1802.

LARribA, Elisabel, "Une presse faite por et par le public dans l'Espagne des Lumières", El Argonauta Español, 2006, 3. Edición digitalizada: <http://argonauta.imageson.org/document70. html $>$ [fecha de consulta:-febrero, 2009].

Leonardo de Argensola, Bartolomé, "Carta del Rector de Villahermosa [...] al Conde de Lemos", en Algunas obras satíricas inéditas de Lupercio y Bartolomé Leonardo de Argensola, publícalas por primera vez, con un estudio crítico que las precede, el conde de la Viñaza, Zaragoza, Imprenta del Hospicio Provincial, 1887, 29-32 (ejemplar de la BNE: 7/107845).

Leonardo de Argensola, Bartolomé, "Menipo litigante. Diálogo de Philopatro. Interlocutores, Arsitas, Menipo", en Algunas obras satíricas inéditas de Lupercio y Bartolomé Leonardo de Argensola, publícalas por primera vez, con un estudio crítico que las 
precede, el conde de la Viñaza, Zaragoza, Imprenta del Hospicio Provincial, 1887, 59-68 (ejemplar de la BNE: 7/107845).

Leonardo de Argensola, Bartolomé, Rimas [publicadas por Ramón Fernández], Madrid, Imprenta Real, 3 ts. 1804-1805 (t. I: Obras de Lupercio; ts. II y III: Obras de Bartolomé). Edición digitalizada: $<$ http://books.google.es/books?id=QQgZAAAAYAAJ\&dq= argensola $\% 2$ Brimas + real\&printsec $=$ frontcover $\&$ source $=$ bl\&ots $=\mathrm{j} 4 \mathrm{TQZ}$ ZeF-E\&sig=Jn0-AIW6jThC9cEX-cC-CRw9n2o\& $\mathrm{hl}=\mathrm{es} \& \mathrm{ei}=\mathrm{jCu} 4 \mathrm{SbbdJtSyjAfLjM2iCQ \& sa=X \& oi=book}$ result\&resnum $=3 \& c t=$ result $>$ [fecha de consulta: febrero, 2009]. Leonardo de Argensola, Bartolomé, Algunas obras satíricas inéditas, publícalas por primera vez, con un estudio crítico que las precede, el conde de la Viñaza, Zaragoza, Imprenta del Hospicio Provincial (ejemplar de la BNE: 7/107845), 1887.

Leonardo de Argensola, Bartolomé, Obras sueltas de Lupercio y Bartolomé Leonardo de Argensola, coleccionadas e ilustradas por el Conde de la Viñaza, Madrid, Imprenta y Fundición de M. Tello, 2 vols. (vol. I: Obras de Lupercio; vol. II: Obras de Bartolomé) (ejemplar de la BNE: AHM/626297-8) 1889.

Lopez, François, Juan Pablo Forner y la crisis de la conciencia española en el siglo XVIII, trad. Fernando Villaverde, Valladolid, Junta de Castilla y León, Consejería de Cultura, 1999 [Juan Pablo Forner et la crise de la conscience espagnole au XVIII e siècle, Bordeaux: Institut d'Etudes Ibériques et Ibéro-américaines de l'Université de Bordeaux, 1976].

Novísima recopilación de las Leyes de España (1805-1809), Madrid, [s.n.], t. IV, libro VIII, título XVII, ley V (ejemplar de la BNE: $\mathrm{R} / 36389$ ).

Pellicer y Saforcada, Juan Antonio, Ensayo de una biblioteca de traductores españoles ... preceden varias noticias literarias para las vidas de otros escritores españoles, Madrid, Antonio de Sancha, 1778.

SÁiz, María Dolores, Historia del periodismo en España. Los orígenes. El siglo XVIII, Madrid, Alianza, $2^{\mathrm{a}}$ ed. rev. y ampl., 1990.

Salvá y Mallén, Pedro, Catálogo de la Biblioteca de Salvá, Valencia, Imprenta de Ferrer de Orga, 1872, t. I., reimp. facsímil, Madrid, Julio Ollero, 1992. 
SChwartz, Lía, "Modelos clásicos y modelos del mundo en la sátira áurea: Los diálogos de Bartolomé Leonardo de Argensola", en Estado actual de los estudios sobre el Siglo de Oro, Manuel García Martín (ed.), vol. I, Salamanca, Universidad, 1993, 75-93.

Schwartz, Lía, "Bartolomé Leonardo de Argensola: Las voces satíricas de un humanista aragonés", Caliope, 8: 2, 2002, 51-73.

ViÑAZA, Cipriano Muñoz y Manzano, conde de la (ed.), Algunas obras satíricas inéditas de Lupercio y Bartolomé Leonardo de Argensola, publícalas por primera vez, con un estudio crítico que las precede, Zaragoza, Imprenta del Hospicio Provincial (ejemplar de la BNE: 7/107845), 1887.

ViÑAZA, Cipriano Muñoz y Manzano, conde de la (ed.), Obras sueltas de Lupercio y Bartolomé Leonardo de Argensola, coleccionadas e ilustradas por [...], Madrid, Imprenta y Fundición de M. Tello, 2 vols. (vol. I: Obras de Lupercio; vol. II: Obras de Bartolomé) (ejemplar de la BNE: AHM/626297-8), 1889.

ZaCour, Norman P. y Rudolf HIRSCH, Catalogue of Manuscripts in the Libraries of the University of Pennsylvania to 1800, Philadelphia, University of Pennsylvania Press, 1965. 